\title{
Kinetic and Mechanistic study of Oxidative Transformation of Some Amino acid by Pyridiniumchlorochromate in DMF-Water Medium
}

\author{
Shilpa Rathor ${ }^{1}$ and B. K. Dangarh ${ }^{2}$ \\ ${ }^{1}$ Research Scholar, Pacific academy of Higher Education and Research University, Udaipur (India) \\ ${ }^{2}$ Asstt. Prof. of Chemistry, Govt. P. G. College, Neemuch, 458441 M.P. (India)
}

\begin{abstract}
Oxidation of L-isoleucine and L-valine by PCC was studied in the presence of perchloric acid in $D M F-\mathrm{H}_{2} \mathrm{O}$ medium at $40^{\circ} \mathrm{C}$. The kinetics of the reaction was followed spectrophotometrically at $\lambda_{\max }=354 \mathrm{~nm}$. The reaction is unit dependence on each of $\mathrm{PCC},\left[\mathrm{H}^{+}\right]$and [substrate]. Michaelis-Menten type kinetics was observed with different amino acid. The reactions were studied at different temperature $[25,30,35,40$, $\left.45,50^{\circ} \mathrm{C}\right]$ and activation parameters were computed. The effect of dielectric constant of the medium on the rate was studied. A mechanism consistent with the observed results has been proposed.
\end{abstract}

Keywords: Oxidation of L-isoleucine, L-valine, PCC, Michaelis-Menten, Spectrophotometrically.

\section{Introduction}

The ultimate goal of our study is to build our knowledge base on the oxidation behavior of some amino acids with PCC. Kinetics of oxidation of methionine [5], oximes [6], unsaturated acids [7], cysteine [8] , alcohols[9] by pyridinium chlorochromate were reported. Dangarh.et.al. reported the kinetic and mechanistic study of oxidative transformation of glycine and alanine [10], 1-isoleucine and nor-leucine [11] and phenylalanine [12] by PDC in aquo-acetic acid medium. Hiran et. al. reported the oxidation of alanine [13] by PCC in DMF-Water medium in the presence of perchloric acid. There seems to be no reports on the oxidation of L-isoleucine and L-valine by PCC. Our literature survey reveals that the oxidation of Amino acid by different oxidants has received limited attention; we are particularly interested to see the mechanism of the oxidation of amino acid by PCC in acidic DMF-Water media.

\section{Materials And Methods}

Pyridiniumchlorochromate was prepared by the method of Corey and Suggs. ${ }^{14}$ and its purity was checked by iodometrically and melting point. All Amino acids (A.R.grade) (SRL) were used as supplied and purity was checked by its melting point. All other chemicals used in this investigation were of analytical reagent grade. Double distilled water was used throughout in the investigation. The rate measurements were carried out at $40^{\circ} \mathrm{C}$ in $\mathrm{HClO}_{4}$ under the condition [amino acid] >> [PCC], in the solvent system of 30-70 \% (v/v) DMF- $\mathrm{H}_{2} \mathrm{O}$. The progress of the reaction was followed by measuring the absorbance of PCC at $354 \mathrm{~nm}$ in one cm cell placed in the compartment of systronics VISISCAN-167 spectrophotometer. The kinetics run were followed for more than $60-70 \%$ completion of the reaction and good first order kinetics were observed.

Stoichiometry and product analysis

\section{Results And Discussion}

To determine the stoichiometry of reaction a known slight excess of pyridiniumchlorochromate was added to a known amount of amino acid, by keeping all other condition of reaction is constant and after 12 hours the residual pyridinium chlorochromate was determined spectrophotometrically at $354 \mathrm{~nm}$. The Stoichiometry of the reaction was found to correspond to the equation. The qualitative product study was made under kinetic conditions i.e. with an excess of substrate over the oxidant. The product of oxidation was corresponding aldehyde i.e. aldehyde and was identified by its 2, 4-dinitro phenyl hydrazine derivative. Nesseler's reagent and lime water test were used to detect ammonium ion and carbon dioxide respectively.

The stoichiometry of the reaction was found to correspond to the equation.

$2 \mathrm{Cr}(\mathrm{VI})+3 \mathrm{RCH}\left(\mathrm{NH}_{2}\right) \mathrm{COOH}+3 \mathrm{H}_{2} \mathrm{O} \rightarrow 3 \mathrm{RCHO}+3 \mathrm{CO}_{2}+3 \mathrm{NH}_{4}^{+}+2 \mathrm{Cr}(\mathrm{III})+3 \mathrm{H}^{+}$

[PCC] [AMINO ACID]

[ALDEHYDE]

\section{Effect of Substrate}

The effect of amino acid concentration on the reaction rate was studied at constant [PCC], [ $\left.\mathrm{HClO}_{4}\right]$, temperature and DMF \% [Table 1]. The reaction rate is increased with increasing of amino acid concentrations. When the logarithms of $\mathrm{k}_{\text {obs }}$ values were plotted against the logarithms of the [amino acid], (Figure 1) a linear plot was obtained. The plot of $1 / \mathrm{k}_{\mathrm{obs}}$ versus $1 /$ [Amino acid], was found to be linear with small positive intercept, 
indicates that Michaelis-Menten type kinetics is followed with respect to Amino acid but the value of intercept is very small indicates that intermediate complex may be highly reactive so concentration will be very small at any time. A similar observation have been found in the oxidation of $\alpha$-amino acid by $\left.\operatorname{Cr}(\operatorname{VI}){ }^{15,16}\right]$.The variation of the rate of oxidation of some amino acids with PCC can be expresses as

$\mathrm{d}[\mathrm{PCC}] / \mathrm{dt}=\mathrm{k}[\mathrm{amino} \mathrm{acid}][\mathrm{PCC}] / K_{\mathrm{M}}+[$ amino acid $]$

\section{Effect of Dielectric constant}

The influence of variation of dielectric constant of the medium was carried out by the changing DMF $(\% \mathrm{v} / \mathrm{v})$ in the reaction medium, keeping other conditions remaining constants and the reaction rate was affected considerably. The rate of reaction increased with an increasing volume percentage of DMF [Table 1]. A lot of theories have been given to quantitative explanation $\left.{ }^{[17,18}\right]$ for the effect of dielectric constant (D) of the reaction medium on the kinetics of liquid phase reaction. For the limiting case of a zero angle of approach between two dipoles or ion-dipole system, Amis $\left[{ }^{19]}\right.$ had shown that in a linear plot of $\operatorname{logk}{ }_{\text {obs }}$ vs. 1/D. The positive slope indicates a positive ion-dipole reaction, while a negative slope indicates the involvement of two dipoles or a negative ion-dipole reaction. In the present investigation a plot of logkobs vs. 1/D shows a straight line with a positive slope, clearly supporting that there is involvement of positive ion-dipole in the rate determining.

\section{Effect of Temperature}

The reaction was studied at different temperatures (298-323 K), keeping other experimental conditions constant. The rate constant of the reaction was found to increase with increasing temperature [Table 2]. From the Arrhenius plot of $\log \mathrm{k}_{\mathrm{obs}}$ versus $1 / \mathrm{T}$, activation energy and other thermodynamic parameters were calculated [Table 3]. The entropy of activation is negative as expected for bimolecular reaction. The negative value also suggests the formation of a cyclic intermediate from non-cyclic reactants in the rate determining step ${ }^{[20]}$. The complex formation is proved by the plot of $1 / \mathrm{k}_{\mathrm{obs}}$ against $1 /$ [Amino acid]. It has been pointed out ${ }^{[21]}$ that if entropy of activation is negative and small the reaction will be slow.

\section{Effect of Pyridine}

It has been observed that there no effect of addition of pyridine on rate of reaction, indicating that PCC is not hydrolyzed in the reaction. Further this shows stability of PCC in the conditions understudy.

\section{Effect of Perchloric acid}

In order to study the effect of $\left[\mathrm{H}^{+}\right]$on the rate the of reaction, kinetic runs were carried out keeping the concentrations of all other reactants are constant and varying the $\left[\mathrm{H}^{+}\right]$with $\mathrm{HClO}_{4}$. From an inspection of the data present in [Table 1], it may be seen that the rate of the reaction increases with increase in $\left[\mathrm{H}^{+}\right]$. When the logarithms of kobs values were plotted against logarithms of the corresponding $\left[\mathrm{H}^{+}\right]$, a linear plot with a positive slope was obtained and indicate that first order reaction with respect to the hydrogen ion concentration. Under the present experimental conditions, the concentration of anion form will be very low and hence the possible species may be either the cation form of amino acids or zwitter ion. With cation as the active species, the rate law predicts a second-order dependence of the rate on $\left[\mathrm{H}^{+}\right]$, which is contrary to experimental results. Protonated amino acid is not involved in the reaction sequence and the zwitter ion is the active species in this reaction.

An amino acid is known to exist in the following equilibria<smiles>[R]C(N)C(=O)O</smiles>

[Amino acid]<smiles>[R]C(N)C(=O)[O-]</smiles>

[Anion]
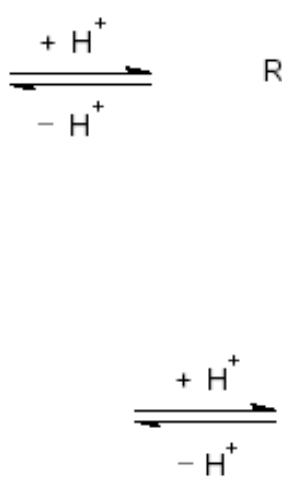<smiles>[R]C([NH3+])C(=O)O</smiles>

[Cation]<smiles>[R]C([NH3+])C(=O)[O-]</smiles>

[Zwitter ion] 
The acid catalysis may well be attributed to a protonation of PCC to yield a stronger oxidant and an electrophile with both the protonated and unprotonated forms being reactive.

Under the present experimental conditions, the protonated chromium (VI) is presumed to be the reactive species since the rate increases with increase in $\left[\mathrm{H}^{+}\right]$. The formation of a protonated species of PCC has been also reported $\left[{ }^{22-24}\right]$.

On the basis of above experimental results, a suitable mechanism is given below;

$\mathrm{PCC}+\mathrm{H}^{+} \rightarrow \mathrm{PCCH}^{+}$

$\mathrm{S}+\mathrm{H}^{+} \rightarrow \mathrm{SH}^{+}$

$\mathrm{PCCH}^{+}+\mathrm{SH}^{+} \rightarrow \quad[$ Complex $]$

$[$ Complex $] \rightarrow \mathrm{R}-\mathrm{CHO}+\mathrm{NH}_{4}{ }^{+}+\mathrm{CO}_{2}+\mathrm{Cr}(\mathrm{IV})$

$\mathrm{Cr}(\mathrm{VI})+\mathrm{Cr}(\mathrm{IV}) \rightarrow 2 \mathrm{Cr}(\mathrm{V})$

$2 \mathrm{Cr}(\mathrm{V})+2 \mathrm{RCH}\left(\mathrm{NH}_{2}\right) \mathrm{COOH}+2 \mathrm{H}_{2} \mathrm{O} \rightarrow 2 \mathrm{RCHO}+2 \mathrm{CO}_{2}+2 \mathrm{NH}_{4}^{+}+2 \mathrm{Cr}(\mathrm{III})+2 \mathrm{H}^{+}$

The overall reaction may be represented as:

$2 \mathrm{Cr}(\mathrm{VI})+3 \mathrm{RCH}\left(\mathrm{NH}_{2}\right) \mathrm{COOH}+3 \mathrm{H}_{2} \mathrm{O} \rightarrow 3 \mathrm{RCHO}+3 \mathrm{CO}_{2}+3 \mathrm{NH}_{4}{ }^{+}+2 \mathrm{Cr}(\mathrm{III})+3 \mathrm{H}^{+}$

On the basis of above mechanism the rate law can be expressed as:

$-\mathrm{d}[\mathrm{PCC}] / \mathrm{dt} \alpha[\mathrm{PCC}]$ [amino acid] $\left[\mathrm{H}^{+}\right]$

Table-1: Effect of [Substrate], $\left[\mathbf{H}^{+}\right]$, and Solvent

$[\mathrm{PCC}]=1 \times 1 \mathbf{1 0}^{-3} \mathrm{M} \quad \mathrm{T}=313 \mathrm{~K}$

\begin{tabular}{|c|c|c|c|c|}
\hline \multirow{2}{*}{$\begin{array}{l}\text { [Substrate] } \\
1^{2} \mathrm{M}\end{array}$} & \multirow[t]{2}{*}[\mathrm{HClO}_{4}]{ X M } & \multirow{2}{*}{$\begin{array}{l}\text { DMF } \\
\text { v/v }\end{array}$} & \multicolumn{2}{|c|}{$\mathrm{K}_{\text {obs }} \times 10^{5} \mathrm{sec}^{-1}$} \\
\hline & & & L-isoleucine & L-Valine \\
\hline 1 & 2 & 30 & 24.41 & 33.62 \\
\hline 1.5 & 2 & 30 & 27.78 & 36.96 \\
\hline 2 & 2 & 30 & 30.24 & 41.64 \\
\hline 2.5 & 2 & 30 & 33.66 & 45.63 \\
\hline 3 & 2 & 30 & 34.58 & 49.74 \\
\hline 1 & 1 & 30 & 9.09 & 5.71 \\
\hline 1 & 1.5 & 30 & 14.81 & 14.77 \\
\hline 1 & 2 & 30 & 24.41 & 33.62 \\
\hline 1 & 2.5 & 30 & 36.23 & 45.90 \\
\hline 1 & 3 & 30 & 42.68 & 62.41 \\
\hline 1 & 2 & 10 & 8.86 & 20.41 \\
\hline 1 & 2 & 20 & 16.35 & 27.48 \\
\hline 1 & 2 & 30 & 24.41 & 33.62 \\
\hline 1 & 2 & 40 & 49.20 & 44.94 \\
\hline 1 & 2 & 50 & 79.26 & 55.34 \\
\hline
\end{tabular}

TABLE NO.2

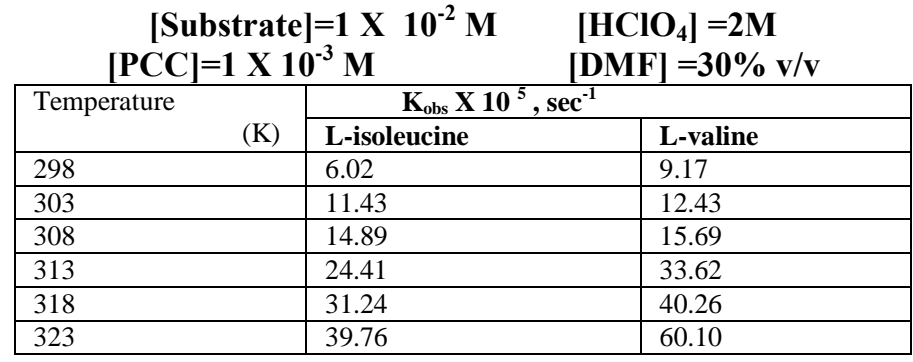

Table No.3: Thermodynamic Parameters

\begin{tabular}{|c|c|c|c|c|c|}
\hline Amino acid & $\log A$ & $\begin{array}{lr}\text { Energy } & \text { of } \\
\text { activation } & \Delta \mathbf{E}^{\neq} \\
\text {kJ mol } & \end{array}$ & $\begin{array}{l}\text { Entropy of activation } \\
\Delta \mathbf{S}^{\neq} \quad \mathrm{J} \mathrm{mol}^{-1} \mathbf{K}^{-1}\end{array}$ & 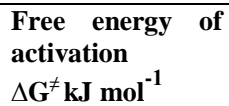 & 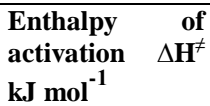 \\
\hline l-isoleucine & 7.90 & 58.83 & -97.53 & 86.76 & 56.23 \\
\hline l-valine & 8.58 & 62.08 & -84.50 & 85.93 & 59.48 \\
\hline
\end{tabular}




\section{Fig-1 Effect of Substrate Concentration}

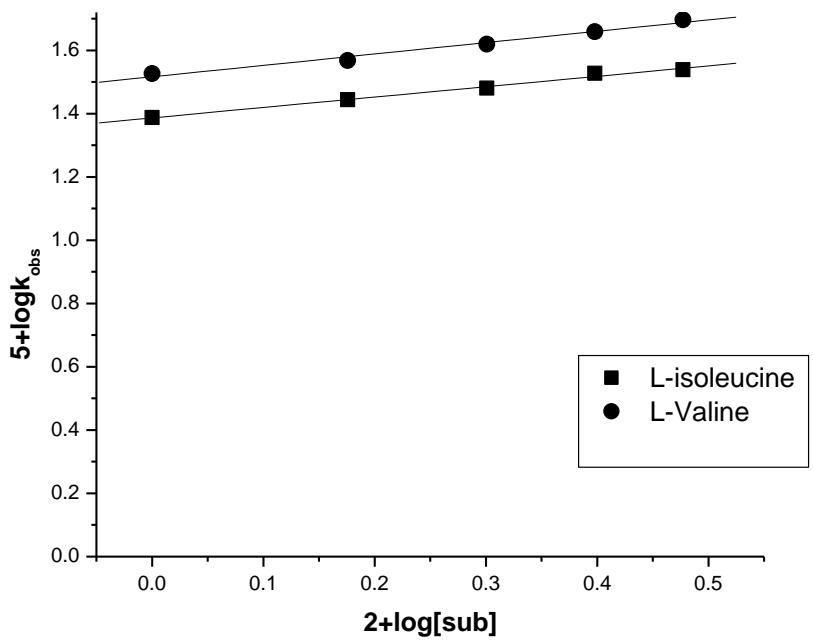

Fig.1.Effect of Substrate Concentration

\section{Conclusion}

At room temperature the reaction between amino acids and PCC is very slow in the low perchloric acid concentration in DMF-water medium. The oxidation of amino acid by PCC is first order with respect to [PCC], [Amino acid] and $\left[\mathrm{HClO}_{4}\right]$. The Zwitter ionic form of amino acid is oxidized to give aldehyde. The reaction was studied at different temperatures. In the temperature range of 298-323 K, Arrhenius equation is valid. The negative value of entropy indicates that the complex $\mathrm{C}$ is more ordered than reactant. The description of the mechanism is consistent with all experimental evidence.

\section{References}

[1]. B.S. Berlett and E.R. Stadtman, J. Biol. Chem., 272, 20313(1997)

[2]. E.R. Stadtman, Science, 257, 1220(1992).

[3]. C.L. Hawkins and M.J. Davies, Biochim. Biophys. Acta, 196, 1504(2001).

[4]. M. K. Mahanti, K. K. Banerji, J. Indian Chem. Soc., 79,31,(2002).

[5]. V. Sharma, P. K. Sharma, K.K. Banerji: J. Indian Chem. Soc., 74 (8), 607(1997).

[6]. A. Bhandari, P. K. Sharma, K.K. Banerji, Indian J. Chem., 40(A), 470(2001).

[7]. R. Kumbhat, V. Sharma, J. Indian Chem. Soc., 81, 745(2004).

[8]. K. K. Adari, A. Nowduri, P. Vani, J Trans. Metal Chem., 31(6), 745(2006)

[9]. B. L. Hiran, S. Jain, C. V. Bhatt, E J Chem., 6(1), 237(2009),

[10]. B.K.Dangarh, S. S. Thakur; IJSR, Vol.5, ISSN No. 2277-8179,(2016).

[11]. B.K. Dangarh and S.S. Thakur. J. Sci. Res. Phar. Chem. Bio.Sci. Vol. (2), 40-44 (2016).

[12]. B.K. Dangarh and S.S. Thakur, Ultra Chem.Vol.12 (1), 9-14(2016).

[13]. B.L.Hiran, M.L.Meena and J. Kunthwal; der pharma chemical, 2(5); 470 478(2010).

[14]. E.J. Core and W.T. Suggs; Tetrahedron Lett., 31, 2647(1975).

[15]. B.L. Hiran, V. Joshi, J. Choudhary, N. Shorgar, P. Verma; Int. J. Chem. Sci., 2(2), 164 (2004),

[16]. S. T. Nandibewoor, P.N. Naik, S. A. Chimitadar; Transition Met. Chem., 33, 405(2008).

[17]. S. amis, "Solvent effects on Reaction Rates and Mechanisms" Academic Press, new York,(1966).

[18]. G. Entelis, R. P. Tiger, "Reaction in Liquid Phase" Wiley, New York, (1976).

[19]. E. S. Amis, J. Chem. Educ., 30, 351(1953).

[20]. U. Bhattacharjee, A. K. Bhattacharjee; Indian J. Chem., 29(A), 1187(1990).

[21]. S. Glasstone, K. J. Laidler, H. Eyring, 'Theory of rate process ' Megraw- Hill, New york. Chapter (III) and (IV), (1941).

[22]. A. Seth, A.Mathur, K. K. Banerji, Bull. Chem. Soc. Jpn.,, 63, 3640(1990).

[23]. P. K. Sharma, K. K. Banerji, J. Indian Chem. Soc., 74, 607(1997).

[24]. R. Kumbhatand, V. Sharma; J. Indian Chem. Soc., 81, 745(2004). 